\title{
AUTOTRADUCCIÓN Y MOVIMIENTO: ¿RUMBO AL SUR, DESEANDO EL NORTE?
}

\author{
POR \\ InÉs García de la Puente \\ Ohio State University \\ Boston University
}

Por eso se la llamó Babel, porque alli Yavé confundió el lenguaje de todos los habitantes de la tierra, y desde alli los dispersó Yavé por toda la tierra. Génesis 11: 9

Desde que la maldición divina terminó con la torre de Babel, los seres humanos hemos estado condenados al destierro por el planeta y a la confusión lingüística - al menos así lo afirma el Génesis. Una exégesis libre del mito bíblico relaciona un tipo de movimiento (el físico) con otro tipo de movimiento (el lingüístico): la translación por el globo trae consigo la necesidad de traducción, esto es, de translación entre lenguas. Las páginas que siguen tratan de mostrar cómo translación física y translación lingüística se entrelazan en un texto literario de estatus peculiar: la autotraducción.

\section{AUTOTRADUCCIÓN Y MOVIMIENTO, TRANSLACIÓN Y LITERATURA}

El motivo de Babel, actualizado en el acontecer histórico, cobra fuerza en los estudios culturales de migración, poscolonialismo, globalización y cosmopolitismo de los siglos XX y XXI. La dispersión por la tierra-viaje, exilio, nomadismo, dislocación, desplazamiento, trans-, in- y emigración, y un largo etcétera- ha sido discutida desde perspectivas tan distintas como las de Jacques Derrida, Félix Guattari, Gilles Deleuze, Edward Said, u Homi Bhabha. ${ }^{1}$

Por su parte, George Steiner explicó en una obra ya clásica en los estudios de traducción, After Babel, que el proceso de traducción es un movimiento hermenéutico. Para Steiner, este movimiento tiene una trayectoria circular que se desarrolla en cuatro etapas. La primera fase es la de confianza en que hay algo que traducir. La segunda etapa es la de agresión y, en ella, de acuerdo con la metáfora de San Jerónimo, el traductor se

\footnotetext{
Ver Slettedahl 5-6 y McClennen, The Dialectics of Exile 1-35.
} 
lleva a casa el significado cautivo, lo rapta violentamente, produciendo un desequilibrio. ${ }^{2}$ La tercera es la fase de incorporación, asimilación y ubicación en el idioma de destino, que puede ir desde la domesticación completa hasta el extrañamiento permanente. La cuarta fase es la que establece reciprocidad y restaura el equilibrio entre los textos en los dos idiomas. Esta última fase enriquece y explica o, para ser más exacta y utilizar el verbo que representa más gráficamente el proceso descrito por Steiner, ilumina el texto. ${ }^{3}$ Aceptemos o no este presunto final feliz, ${ }^{4}$ la traducción conceptuada como movimiento circular puede ser aplicada y "perfeccionada" en la autotraducción: si el traductor, a través de su profundo análisis y pese a su apropiación del texto, ilumina el original, el autotraductor debería iluminar sin raptar, puesto que como autor, no necesita apropiarse del texto de partida, cerrando así el círculo hermenéutico con menos pérdidas para el texto de salida. La práctica autotraductora, sin embargo, demuestra que raramente es éste el caso, ${ }^{5}$ llevando así a una cuestión esencial: ¿cuál es el estatus de la autotraducción? ¿Se trata de una traducción o de un texto original?

Debido a la falta de unanimidad en la respuesta a estas preguntas, la traductología ha evitado durante años el estudio de la autotraducción. ${ }^{6}$ Entre quienes la han tratado -y cada vez son más- sigue sin haber acuerdo. En la década de 1970 Anton Popovic afirmó que una autotraducción es una traducción y no un nuevo original (citado en López López-Gay 112). Brian T. Fitch subrayó la imposibilidad de clasificar autotraducción ni como traducción, ni como original. ${ }^{7}$ En la entrada sobre autotraducción en la Routledge Encyclopedia of Translation Studies, Rainier Grutman considera la autotraducción traducción (no en vano su artículo aparece en una enciclopedia sobre traducción), aunque también recalca la importancia de la innovación en el proceso, sobre todo en los casos de "delayed auto-translation" (20). En un muy breve artículo, Francesc Parcerisas

2 Las expresiones que usa Steiner son: "meaning brought home captive by the translator" $y$ "appropriative "rapture"" (Steiner, After Babel, 314 y 316 respectivamente).

3 En el original inglés, "illumine" (Steiner 316). El pasaje completo que he resumido ocupa las páginas 312-319.

4 Sobre los potenciales defectos del texto traducido se ha escrito mucho; Venuti, por ejemplo, advierte que la interpretación proporcionada en el texto traducido será inevitablemente parcial (61). El propio Steiner insiste en que el ideal nunca se cumple (317-18).

5 Grutman cita a Menakhem Perry, quien a su vez se basa en Toury, para afirmar que la condición de autor del autotraductor le permite alejarse del texto fuente hasta puntos que no se aceptarían en un traductor (“Auto-translation" 18). Un ejemplo clásico de libertad autotraductora es el de Vladimir Nabokov. Pese a defender la literalidad para la traducción -su versión inglesa de Eugenio Onegin sigue estas premisas hasta el punto de crear una traducción que Grayson califica de "scientific" (17)- en sus autotraducciones Nabokov reescribe con enorme libertad (3-4).

6 Hokenson y Munson 2-5, 146. Comentarios sobre la inexistencia de estudios de autotraducción se pueden encontrar en Fitch 21 y, más recientemente en Grutman, "Beckett and Beyond" 189.

7 Analizando la autotraducción que Beckett hizo de Ping, la conclusión de Fitch es que no entra en ninguna de las categorías conocidas de traducción, y que la autotraducción tiene unas características particulares que le otorgan un estatus distinto al de la traducción (78).

$111 \frac{\text { Revista Iberoamericana, Vol. LXXXIII, Núm. 258, Enero-Marzo 2017, } 103-117}{\text { ISSN 0034-9631 (Impreso) }}$ 
destaca tanto lo que de traducción como de creación original tiene la autotraducción (13). Patricia López López-Gay insiste en que la autotraducción es, ante todo, y a pesar de que no encaje en los moldes traductológicos corrientes, traducción (112-13). Por el contrario, Jacqueline Risset ve en la autotraducción "a complete rewriting" (3). ${ }^{8}$ También en esta línea, Irina Mavrodin defiende que la autotraducción es siempre reescritura, llegando a considerar la autotraducción "obra monumento" y la traducción "obra simulacro" (citado en López López-Gay 113). Gérard Genette considera que el resultado de la autotraducción son dos versiones de una obra (238-39). ${ }^{9}$ Ciertamente, la autotraducción se beneficia de que en el proceso de reapropiación del texto de salida, el autor-traductor no cometerá (o no debería cometer) errores de comprensión. Como bilingüe y bicultural, el autotraductor podrá adaptar su obra para el nuevo público con la ventaja de quien, igual que el traductor, conoce la cultura de llegada e, igual que el autor, tiene potestad para decidir qué y cómo decirlo. En la práctica, el autotraductor, en tanto autor, se toma grandes licencias de traducción. ${ }^{10}$

Mi breve estudio ni quiere ni puede resolver este dilema, pero tampoco, dada su importancia, puede obviarlo. Por ello, el concepto de autotraducción que subyace en las siguientes páginas es flexible y combina ambas vertientes. En vez de definir por negación y oponer los dos aspectos como si se eliminaran mutuamente, propongo que pensemos la autotraducción como constituida por dos mitades complementarias que conviven en armonía en el espacio del original y de la traducción. En cuanto a recreación, la autotraducción es, efectivamente, un texto original; en cuanto a traducción, transpone a otro idioma un texto previo. Así vista, la autotraducción se beneficiará del proceso creativo autorial y del traductor.

De este modo, volviendo al movimiento hermenéutico que Steiner describió para la traducción, éste se puede aplicar plenamente a la autotraducción, aunque con las licencias necesarias para incluir la pluma del autor-traductor en el proceso. ${ }^{11}$ En la segunda fase, el traductor no trae, sino que re-trae, o lleva de nuevo de vuelta a casa el texto primero. La fase tercera se convierte en ocasiones en una "naturalización" completa en el idioma de destino. Esto lleva a que en la cuarta fase se restaure inevitablemente el equilibrio pero, a diferencia de la traducción, no siempre con el texto de salida, sino con los designios del autor-traductor. El nuevo texto generará luz, y no sólo por motivos

\footnotetext{
8 Sin embargo, este artículo se refiere exclusivamente a la traducción al italiano que hizo Joyce de dos pasajes de lo que más adelante se convertiría en Finnegans Wake, una autotraducción cuyas peculiaridades han señalado también otros estudiosos.

9 Genette se menciona en concreto a las autotraducciones de Nabokov y Samuel Beckett.

10 Ver nota 4.

11 En un artículo centrado en caracterizar la autotraducción como diálogo, Klimkiewicz no obstante destaca la creación de rutas y espacio como parte del proceso de autotraducción: "[...] the writer explores the zones of contact and transfer taking place in a multidirectional and multilingual dialogue, creating at the same time a dense space, a network of routes and passages [...]" (192).
} 
externos al texto, sino por las libertades de las que ha disfrutado en su reconfiguración por quien lo ha escrito por segunda vez, y para otro receptor.

También en la crítica literaria se ha trabajado la noción de movimiento implícita en la traducción. Salman Rushdie jugaba en su ya canónico ensayo "Imaginary Homelands" con el sentido lingüístico y espacial de "translation": "The word 'translation' comes, etymologically, from Latin for 'bearing across'. Having been borne across the world, we are translated men" (17); verter "translated men" al castellano pone al traductor en la disyuntiva de tener que decidir entre "traducidos" o "trasladados".

En los últimos años, traducción y translación han proporcionado un paradigma de análisis productivo para varias monografías que entrelazan el estudio literario y cultural. Eva Karpinski en Borrowed Tongues reflexiona, desde una perspectiva feminista, sobre la relación conceptual entre traducción y escritura autobiográfica femenina de emigración, donde el traslado espacial corre parejo con la traducción lingüística y cultural (6-40). Loredana Polezzi en Translating Travel se centra en la literatura de viajes italiana en traducción inglesa; su tercer capítulo "Travel as/and Translation" estudia las conexiones teóricas entre viaje y traducción, y concluye que el análisis comparado es necesario para observar la nueva capa de translación que la traducción supone para el relato de viajes, ya complejo en cuanto a translación antes de ser traducido (77-113). Translation and Identity, de Michael Cronin, demuestra la relación entre traducción y migración, haciendo hincapié en el papel esencial de aquélla en la creación de identidad cultural (43-74). A pesar de las diferencias entre estos estudios, los cuatro tienen en común el abordar, desde el análisis literario, el estudio de la relación entre traducción y translación, esta última entendida ya como movimiento en cuanto a traslado geográfico o cronológico, ya como migración.

Literatur in Bewegung (traducida al castellano como Literatura en movimiento) de OttmarEtte es, probablemente, el estudio más completo sobre las múltiples posibilidades de conceptuar la literatura como movimiento. Ette sugiere que el movimiento en la literatura está constituido por los lugares literarios de viaje y por el movimiento hermenéutico en el texto. ${ }^{12}$ Aunque Ette aplica reflexiones sobre movimiento a un amplio espectro de textos literarios, la literatura de viajes tiene un protagonismo especial: entre géneros literarios, entre culturas y entre distintos lugares geográficos, todo en ella apunta a la movilidad. No es sorprendente que tanto Ette como Polezzi (1-2) hayan insistido en la hibridez de este tipo de textos. ${ }^{13}$

Otros textos estrechamente relacionados con la literatura de viajes compartirán con ella la importancia que cobra el movimiento. Me refiero a la llamada literatura de

12 Ette, Literatur 52; Literatura 62.

13 Resaltando la hibridez de la literatura de viajes, Ette insiste en que es "friktional” (Literatur 43-48; Literatura 38-42).

$111 \frac{\text { Revista Iberoamericana, Vol. LXXXIII, Núm. 258, Enero-Marzo 2017, } 103-117}{\text { ISSN 0034-9631 (Impreso) }}$ 
migración y a un subtipo de ésta, la literatura de exilio. ${ }^{14}$ Con una larga tradición, la producción literaria de exiliados que reflexiona sobre su condición es importante en el continente americano. Esto no se les ha pasado por alto a Amy Kaminsky en After Exile y a Sophia McClennen en The Dialectics of Exile. Ambos estudios se ciñen al exilio en un medio lingüístico-cultural específico, el hispanohablante. Es precisamente en este tipo de obras constituido por los relatos de exiliados hispanoamericanos en el que se enmarca el texto a estudiar en este artículo: Rumbo al Sur, deseando el Norte.

RUMBO AL SUR, DESEANDO EL NORTE

Rumbo al Sur, deseando el Norte (que en adelante abreviaré Rumbo) es el primer volumen de las memorias del escritor argentino-estadounidense-chileno Ariel Dorfman. ${ }^{15}$ Dorfman escribió primero la versión inglesa, Heading South, Looking North (en adelante Heading), que tradujo después al castellano. ${ }^{16}$ Estas memorias narran el viaje vital de su autor-protagonista-narrador, ${ }^{17}$ una existencia ciertamente definida por el movimiento entre subcontinentes y hemisferios, lenguas y culturas.

El exilio ha marcado el discurso literario que Dorfman ha creado de su vida. Los títulos de sus memorias no son más que una obvia prueba de ello: Heading South, Looking North y Rumbo al Sur, deseando el Norte ya apuntan a que en la obra se va a hablar de "muchos exilios". ${ }^{18}$ Feeding on Dreams: Confessions of an Unrepentant Exile, sus segundas memorias, reinciden en la importancia del exilio en su vida ya desde un paratexto que anuncia inequívocamente la condición del protagonista, y luego también en su tráiler promocional. ${ }^{19}$

Si la autotraducción y la literatura se caracterizan por el movimiento que las genera y por el movimiento que transmiten, la condición de memorias de exilio autotraducidas deberían hacer de Rumbo una obra especialmente móvil. Ya Rushdie destacó la importancia del movimiento en lo que él llama "literature of migration". ${ }^{20}$

14 En su estudio de la literatura hispana inmigrante en Estados Unidos, Kanellos propone dividirla en inmigrante, nativa y exiliada (Hispanic Immigrant Literature 14; 23-24).

15 En las siguientes páginas citaré de la versión española, publicada en Barcelona.

16 Ver Rumbo 11, y McClennen, Ariel Dorfman 345, nota 51. No se trata, pese a que tanto la edición inglesa europea como la castellana sudamericana se publicaran en 1998, de una autotraducción simultánea, pues Dorfman completó primero la versión inglesa, y luego la tradujo al castellano. Sobre la autotraducción simultánea, ver Grutman, "Auto-translation” 20.

17 Hago eco del "pacto autobiográfico" defendido por Philippe Lejeune.

18 En el "Prefacio a modo de dedicatoria" de Rumbo, Dorfman escribe "Es mi historia, la de mis muchos exilios y mis tres países y las dos lenguas [...]"

19 "Watch trailer." 26 de julio de 2013. <http://www.adorfman.duke.edu/>

${ }^{20}$ En su ensayo sobre Günter Grass, Rushdie destaca la importancia de la visión migrante, y por tanto del movimiento migratorio en la literatura, desde la experiencia del escritor hasta la perspectiva que reflejan sus obras $(277-80)$. 
Efectivamente, el movimiento está presente en ella en varias esferas. Rumbo es el relato de una existencia en movimiento -la diégesis es una continua translación. Unas memorias, y en especial unas como éstas, marcadas por el exilio, tienen muchos rasgos en común con la literatura de viajes: hay movimiento del autor, del paisaje contemplado, de las gentes descritas, de lenguas, de cultura, de escritura. Por otro lado, en tanto autotraducción, Rumbo añade una esfera de movimiento que no estaba presente en Heading: primero, porque la mera traducción, como indicaba Steiner, supone movimiento. Segundo, y en esto me centraré a partir de ahora, porque la autotraducción va a poner el texto en movimiento mediante la creación de nuevos espacios y de relaciones entre ellos. Para mostrar que en la autotraducción el espacio se recartografía y los movimientos mutan, propongo un estudio comparado de las dos versiones lingüísticas: ${ }^{21}$ mi mirada se concentrará en el texto castellano sin perder nunca de vista su continuo diálogo con el inglés.

\section{Caso 1}

Empiezo mi análisis con una cita del capítulo doce de Rumbo que se refiere al Sumario de la Historia Natural de las Indias de Gonzalo Fernández de Oviedo. Es precisamente a este tipo de obra a la que Ette dedica casi todo el segundo capítulo de su estudio del movimiento en la literatura (Literatur 85-117; Literatura 69-91): los escritos, a caballo entre el diario y el libro de viajes, de los primeros europeos que estuvieron en América. En el texto que cito a continuación, Dorfman reflexiona sobre los paralelismos del Sumario con su propia obra:

Empecé a fascinarme con ese período en la historia cuando otros exploradores, similares a mí, habían llegado a estas tierras, traduciéndolas por primera vez a un idioma europeo y para una mirada extranjera. (Rumbo 262)

I became fascinated with the moment in history when other explorers such as myself had come upon this land and translated it for the first time into a Western language and for a Western gaze. (Heading 192)

Las dos versiones son parecidas, pero el autor-traductor se ha tomado ciertas libertades. Si en inglés tanto "language" como "gaze" están adjetivados con "Western", en castellano el "idioma" es "europeo", y la "mirada" es "extranjera". Al traducirse, Dorfman ha restringido y ampliado a la vez el espacio cultural denotado en la frase. Por un lado, si observamos "idioma europeo" frente a "Western language", vemos que "europeo" define el grupo de idiomas occidentales a los que se refiere de manera más

21 Sigo, por tanto, la misma vía que propuso Polezzi para el estudio de la literatura de viajes traducida (104-105). 
restrictiva que "Western language", que por su parte engloba toda lengua occidental y no sólo las del Viejo Mundo. ${ }^{22}$ Por otro lado, "mirada extranjera" aumenta las delimitaciones de "Western gaze": de ser exclusivamente occidental en inglés, en castellano pasa a abarcar todo lo que es ajeno a la mirada del Nuevo Mundo.

El espacio que se crea en este pasaje es, como consecuencia, distinto en castellano y en inglés. En inglés aparecen dos espacios diferenciados en oposición binaria: lo "Western" frente a todo lo americano, Occidente frente al Nuevo Mundo. Del texto castellano emergen tres espacios: América, Europa y lo extranjero. Incluso a América se refiere en plural: "estas tierras" (frente a 'esta tierra', otra posible y más exacta traducción de "this land"), quizá para remarcar su diversidad. Los tres espacios se presentan en una gradación de otredad ascendente respecto al Nuevo Mundo: lo americano, lo europeo y lo extranjero. Es decir, la oposición América-Occidente de Heading es inexistente en Rumbo: el texto español transmite un mapa espacial con tres zonas, donde hay una gradación de tres espacios: partiendo de lo americano, se llega a lo extranjero pasando por Europa.

\section{Caso 2}

Más adelante en el capítulo doce, Dorfman sigue reflexionando sobre el texto de Fernández de Oviedo, concretamente sobre la parte del Sumario en la que menciona la dificultad para nombrar adecuadamente el tigre americano:

Aunque mis simpatías estaban del lado del tigre -robado de su hogar, metido en una jaula y enviado a ultramar, a miles de kilómetros para regocijo de ojos europeos que nada comprendían [...] (Rumbo 263)

Though my sympathies were with the tigre, stolen from its home, shipped thousands of miles away to be paraded in front of uncomprehending European eyes [...] (Heading 192-93)

La aparición en castellano de las oraciones subordinadas "metido en una jaula y enviado a ultramar," ausentes del inglés, parece cumplir dos objetivos. Por una parte, al hacer referencia directa al confinamiento del tigre con "metido en una jaula", recalca la limitación espacial. Por otra parte, "enviado a ultramar”, que se reitera a continuación en "[enviado] a miles de kilómetros", pone de relieve la separación del lugar de origen y la lejanía de Europa, ese "ultramar" desconocido para América. La opresión del tigre es asfixiante; su cruel sometimiento y forzado exilio de su tierra natal, su confinación

${ }^{22}$ Habitualmente relacionamos en castellano lo "europeo" con lo "occidental," y esta identificación funciona también en inglés. Por lo tanto, el que Dorfman optara por "Western" en vez de por "European" refuerza mi observación. 
a una jaula y su envío a Europa a través del Atlántico cobran una fuerza en castellano que estaba tamizada en inglés. La jaula (referenciada explícitamente sólo en Rumbo, pues Heading no da detalles sobre cómo se mete al tigre en el barco) representa lo contrario a la libertad; es dentro de ella donde en castellano se transporta al tigre de América a Europa. Objeto y símbolo de la usurpación de la libertad del tigre, opuesta al mundo salvaje de América, la jaula es un no-espacio que llevará al animal a la locura y muerte en Toledo.

\section{Caso 3}

Los siguientes párrafos del capítulo sexto hablan sobre el Dorfman niño durante su primer exilio en Nueva York. Enamorado de la cultura estadounidense y totalmente adaptado a su entorno norteamericano, en la época a la que se refiere este pasaje lleva años sin utilizar su lengua materna. Estados Unidos y el inglés son el entorno en el que el protagonista se identifica, donde se siente en casa. En las líneas que siguen se cuentan los sentimientos del niño cuando sus padres piensan que puede ser posible volver a Argentina:

Ese fue el motivo, se me ocurre, de que reprimiera con tanta ferocidad mi lado castellano, porque las amenazas de que pudiera despertar estaban conectadas a un lugar verdadero en el mundo, un espacio recalcitrantemente físico que no podía borrar yo del mapa real del mundo con la facilidad con que había borrado el lenguaje que se alojaba perversamente en ese espacio.

En forma un tanto mítica, el castellano se me antojaba como uno de esos ogros en los fairy tales que habitan los escondrijos más remotos de un castillo aprontándose para salir, o tal vez el cuento de hadas que más le venía a mi idioma natal era ese en que el hijo más joven de la familia es abandonado en el bosque o se lo vende como esclavo y luego años más tarde resucita, siempre siempre resucita.

Pero mi castellano no volvería de la muerte. Para eso estaba "Perón, Perón, qué grande sos". Ese insólito aliado mío permitió a este compatriota suyo seguir a la caza de la vida norteamericana [...] (Rumbo 90-91)

That was, I believe, the reason why I so ferociously repressed my Spanish self, because his threats to awaken, like a monster in the recesses of the castle in the fairy tales, his threats to return from the dead like the youngest brother sold into slavery, were connected to a real place in the world, a recalcitrantly physical space that I could not erase from the real map of the world the way I had erased the Spanish perversely localized there.

But my bizarre ally, General Perón, saved me for English and America [...] (Heading 63)

El concepto de regreso domina este pasaje. En el primer párrafo, "reprimiera" se refiere a frenar, a evitar la vuelta del castellano; el "despertar" de la lengua

$111 \frac{\text { Revista Iberoamericana, Vol. LXXXIII, Núm. 258, Enero-Marzo 2017, } 103-117}{\text { ISSN 0034-9631 (Impreso) }}$ 
castellana se asocia a volver a Argentina ("un lugar verdadero en el mundo, un espacio recalcitrantemente físico"). En el segundo párrafo, "aprontándose para salir” transmite la idea del castellano como ogro acechante que se prepara para volver al narrador; "resucitar" es la vuelta de entre los muertos; incluso cuando se busca un cuento de hadas que exprese la situación del protagonista con su "idioma natal”, el giro idiomático elegido incluye un verbo que se mueve hacia el hablante: "venía". En el tercer párrafo, "volver de la muerte" repite el concepto de resucitar con el que terminaba el párrafo anterior. Amenazas, perversamente, ogros, escondrijos remotos de un castillo, abandono en el bosque, muerte: la posibilidad del regreso evoca un ambiente casi malvado, pinta unos espacios tétricos, sombríos. Sin embargo, el regreso no llega a ocurrir, y la familia se queda en Nueva York. Esta no-realización del traslado familiar supone la no-realización del castellano: la negación del traslado físico equivale a la negación de la translación lingüística en un pasaje en el que se relacionan explícitamente lugar y lengua. La lengua habita espacios y, en cierto modo, es esos espacios. El castellano se personifica (es reprimido, no vuelve de la muerte), incluso "se ogrifica" y habita las profundidades del castillo; el castellano está conectado a "un espacio recalcitrantemente físico". Idioma y lugar son interdependientes: la translación de uno es la translación del otro.

La resurrección es el tipo de retorno que cobra mayor protagonismo en este pasaje. Resucitar es el regreso por excelencia: la vuelta del mundo de los muertos al de los vivos, un cambio transcendente. La resurrección del hermano abandonado es una imagen especialmente evocadora, con ecos bíblicos: ${ }^{23}$ la resurrección del hermano simboliza la resurrección del castellano, del bilingüismo aborrecido por el Dorfman niño. Pero al contrario que en el Nuevo Testamento, en Rumbo/Heading el peculiar "don de lenguas" que pudiera ser el bilingüismo de Dorfman se parece más a una maldición de Babel que a un don del Espíritu Santo.

Si comparamos las versiones inglesa y castellana, salta a la vista que el texto castellano aumenta el inglés en volumen. Esto tiene consecuencias también para el contenido: Rumbo amplía lo dicho en inglés, lo reelabora, y establece un diálogo entre los dos idiomas.

La parte "like a monster in the recesses of the castle in the fairy tales, his threats to return from the dead like the youngest brother sold into slavery", que en Heading es parte de un único párrafo, en Rumbo da pie al segundo párrafo y a la primera línea del tercero. Si en Heading la metáfora del ogro como su "Spanish self" se hace explícita desde el primer párrafo, en Rumbo no aparece hasta el segundo párrafo. Como consecuencia, este pasaje de Rumbo pierde la cohesión del texto inglés. Si leemos con atención "Ese fue el motivo, se me ocurre, de que reprimiera con tanta ferocidad mi

23 Pienso en Pentecostés, cuando, de acuerdo con la Biblia, los Apóstoles predican y son entendidos en todas las lenguas (Hechos de los Apóstoles 2: 1-6). 
lado castellano, porque las amenazas de que pudiera despertar estaban conectadas [...]" (90), nos damos cuenta de que el verbo "despertar" no encaja todo lo bien que pudiera; la reacción de algo reprimido es rebelarse o liberarse, no despertarse. Este "despertar" se integra, sin embargo, en el segundo párrafo, donde se elabora el motivo del ogro que duerme: despertar encaja aquí perfectamente, pues es la acción naturalmente consecutiva a dormir. Si en inglés "awaken" y "monster" aparecen en secuencia lógica, dando continuidad al texto, en castellano se produce una ligera cesura: hay que esperar al siguiente párrafo para volver al hilo expositivo que hablaba del ogro. La traducción, el traslado de idioma, ha causado un movimiento físico en el texto y una transposición de imágenes y contenido.

"[H]is threats to return from the dead"(63) desaparece en Rumbo en el primer párrafo para reaparecer parafraseado en español en la primera frase del tercer párrafo: "Pero mi castellano no volvería de la muerte" (91). Esta frase retoma la interrumpida traducción del inglés y, a la vez, sigue el hilo con que terminaba el párrafo anterior castellano: "resucita, siempre siempre resucita" (91). Por otra parte, "resucitar" conceptualiza y reincide sobre "return from the dead" (63). La palabra resurrección ('resurrection') no aparece en inglés, aunque su contenido se explique con "return from the dead". El castellano utiliza abiertamente el concepto de resurrección y, como si un retorno de la muerte no fuera suficiente, se reduplica todo el sintagma: "resucita, siempre siempre resucita" (91).

La repetición de palabras, la reincidencia en la idea de regreso y resurrección en estos tres párrafos de Rumbo crea un movimiento circular, de continua ida y vuelta; el texto se construye como una espiral. Por el contrario, en Heading sólo aparece una vuelta, la de entre los muertos, dejando una estructura lineal mayoritaria en el pasaje. Sin embargo, o precisamente a causa de esta diferencia en la estructuración del texto, en el uso de recursos, y en la explotación de la idea de retorno, se establece un diálogo entre Heading y Rumbo: ideas que el inglés desarrollaba en línea, consecutivamente, en castellano se retoman repetidamente, se rizan, y crean una circularidad dentro del texto castellano que, a la vez, remite al inglés.

\section{Caso 4}

En el pasaje que sigue, también del capítulo seis, se está contando cómo, esta vez, sí que llega el momento de dejar Estados Unidos y volver a Sudamérica. Si en el anterior pasaje fue el triunfo del General Perón lo que evitó la vuelta a Argentina, ahora será la caza de brujas del senador Joseph McCarthy la que obligue a los Dorfman a abandonar Nueva York y trasladarse a Santiago de Chile.

¿Qué hubiera dicho [Joseph McCarthy] de saber que su limpieza de Norteamérica tendría un efecto paradójico, enviando a un niño argentino que adoraba a Disney de vuelta a 
la América [L]atina donde las podridas manzanas de la izquierda latinoamericana lo iban a corromper y llevarlo a escribir la primera crítica antiimperialista de ese parangón del capitalismo, el Pato Donald? Qué extraño, ¿no? Que Joe McCarthy me mandara a los brazos de Cantinflas. (Rumbo 106)

What would he [Joseph McCarthy] have said if he had known that his cleansing of America would have the unintended effect of sending an Argentine kid who adored Disney back to Latin America; where he would be corrupted by all the rotten apples down there and end up writing the first left-wing critique of that most imperialist of creatures, Donald Duck? Think of it: Joe McCarthy parting me from Charlie McCarthy. (Heading 74)

En las frases de centro del párrafo leemos: “[...] las podridas manzanas de la izquierda latinoamericana lo iban a corromper y llevarlo a escribir [...]" y "[...] he would be corrupted by all the rotten apples down there and end up writing [...]" Mientras el sujeto en castellano son las manzanas, en inglés es el miso Dorfman. Consecuentemente, en inglés es él quien "[would] end up writing" mientras que en castellano son las manzanas las que lo llevan a escribir. El español da preferencia a la idea de que, una vez más, el destino lo lleve, lo traslade: el sentido figurado de la expresión está en referencia al sentido directo de unas líneas más arriba, "enviando" (106). La elección del giro idiomático castellano no es accidental, igual que en el pasaje anterior la elección de "venía" tampoco era casual. ${ }^{24}$ El castellano lo "lleva" a escribir: la translatio lingüística lleva a la translatio espacial implícita en la perífrasis verbal.

Rumbo y Heading difieren en la metáfora final de este pasaje. En inglés se juega con la homonimia parcial de Joseph McCarthy, el senador republicano, y de la marioneta Charlie McCarthy, una estrella en la industria del entretenimiento de la época. Dorfman aprovecha esta coincidencia para criticar al senador adalid de la lucha contra el comunismo, poniéndolo implícitamente en el mismo plano intelectual que una marioneta tonta y absurda. Con la frase "Joe McCarthy parting me from Charlie McCarthy" (90) se crea una metáfora continuada que, de visualizarla, consistiría en el senador arrancando cruelmente al inocente niño de los brazos de la marioneta.

En castellano el nombre de la marioneta es sustituido por el famoso personaje mexicano interpretado por Mario Moreno, Cantinflas. Con ello Dorfman aproxima el texto al contexto cultural receptor: pocos hispanohablantes conocen a Charlie McCarthy, mientras que Cantinflas se popularizó en toda América Latina y en España. Esto es algo que Dorfman, igual que otros autotraductores, hace a menudo: tomarse grandes licencias de traducción para adecuar el texto a la cultura del idioma de destino. En este caso, el ajuste cultural conlleva un sacrificio formal: se pierde el juego de palabras

\footnotetext{
${ }^{24}$ Me refiero a "el cuento de hadas que más le venía a mi idioma natal", analizado en el apartado anterior.
} 
McCarthy-McCarthy. Pero gracias a ello, se crea una metáfora muy gráfica, transparente para cualquier hispanohablante, que también se burla de Joseph McCarthy, al que esta vez se representaría lanzando al mismo inocente niño con la misma crueldad a los brazos de Cantinflas.

Esta sustitución de Charlie McCarthy por Cantinflas deja huellas en el mapeo del movimiento en la autotraducción. Al hacer referencia al senador estadounidense mandando al Dorfman niño a los brazos de Cantinflas, el castellano traza un movimiento con trayectoria de EE.UU. a Latinoamérica, un traslado de norte a sur, de vuelta a su hemisferio natal. Este movimiento con sentido norte-sur está ausente en el inglés: Heading re-flexiona, se dobla sobre sí mismo, como una flecha cuya cabeza apunta su cola en un círculo de vuelta: al arrebatar al niño de los brazos de Charlie McCarthy se insiste en la separación de Norteamérica, no en su propulsión de vuelta hacia el Sur, pues Dorfman queda en brazos del senador. Los movimientos que se describen en las dos obras son distintos: si el inglés deja a Dorfman en el norte, el castellano lo lleva al sur.

\section{Caso 5}

Quiero cerrar estos estudios de caso con una reflexión sobre los subtítulos. La versión castellana argentina de Rumbo se subtitula "Un romance en dos lenguas" y la española "Un romance bilingüe"; la inglesa, como dije, "A Bilingual Journey". "Journey" se convierte, pues, en "romance" y no en el esperable "viaje". Esta decisión en el paratexto tiene dos interpretaciones posibles. Una defendería que el subtítulo es otro caso de variaciones de movimiento en la autotraducción: mientras el inglés viaja, el castellano se queda, pero jugando con la polisemia del romance: este género literario se entiende popularmente como historia de amor. Otra defendería que, pese a la selección de distintos sustantivos para evocar el movimiento, ambos subtítulos insisten en la idea de viaje: el subtítulo nos estaría diciendo que la literatura (el romance en cuanto a género literario), como el viaje, es movimiento. No encuentro argumentos para decantarme más por una u otra interpretación, pero cualquiera de ellas es relevante para este estudio: ambas son otra pequeña prueba a favor de que el movimiento, y sus cambios, juegan un importante papel en la autotraducción.

\section{ConClusión}

Al comenzar este ensayo anunciaba cómo el concepto de movimiento permea Rumbo: en cuanto a memorias de múltiples exilios, es un ejemplo casi perfecto de "literatura en movimiento" y, en cuanto a (auto)traducción, lo caracteriza el movimiento exegético. Después he intentado ofrecer un análisis detallado de cómo se presenta el movimiento y el espacio en y entre el que transcurre la obra, resaltando cómo se compara con Heading, el texto inglés previo.

El análisis ha demostrado que unas memorias de exilio autotraducidas multiplican 
el movimiento de la obra inicial. Rumbo y Heading son partícipes del movimiento que el subgénero de las memorias de exilio conlleva, donde el espacio cambiante cobra a veces tanto protagonismo como el protagonista que lo narra. Rumbo, además, añade movimientos y espacios inexistentes en Heading, o modifica los que ya se describían en inglés: la configuración espacial y el movimiento que se evoca en las dos obras varían.

Los ejemplos nos dejaron ver cómo, si Heading oponía el binomio América y Occidente, Rumbo hacía una oposición gradual entre América, Europa y lo extranjero; Rumbo creó un no-espacio con la jaula que negaba al tigre su libertad y su origen; si en Heading la temida lengua castellana se movía más o menos en línea, en Rumbo resurrección y circularidad caracterizaban su trayectoria y ponían las dos versiones lingüísticas en diálogo; si en inglés Joseph McCarthy se quedaba con el niño Ariel, en castellano Cantinflas se lo llevaba al hemisferio sur. Todos estos pasajes muestran que los lugares que aparecen en el texto, y las relaciones entre ellos, no son las mismas en los dos idiomas.

Espacio y movimiento se han recartografiado en el texto autotraducido. Los mapas que resultan de una y otra versión lingüística no son calcos hechos con papel transparente. La autotraducción redibuja, se recrea, y re-crea los puntos cardinales: entre el rumbo al sur y el deseo del norte, el castellano y el inglés siguen viajes distintos.

\section{OBRAS CONSULTADAS}

Cronin, Michael. Translation and Identity. London: Routledge, 2006.

Dorfman, Ariel. Feeding on Dreams: Confessions of an Unrepentant Exile. Boston: Houghton Mifflin Harcourt, 2011.

Heading South, Looking North: A Bilingual Journey. 1998. New York: Penguin, 1999.

Rumbo al Sur, deseando el Norte: Un romance en dos lenguas. Barcelona: Planeta, 1998.

"Watch Trailer." 26 de julio de 2013. <http://www.adorfman.duke.edu/>

Ette, Ottmar. Literatur in Bewegung: Raum Und Dynamik Grenzüberschreitenden Schreibens in Europa Und Amerika. Weilerswist: Velbrück Wissenschaft, 2001.

Literatura en movimiento: Espacio y dinámica de una escritura transgresora de

fronteras en Europa y América. Rosa María S. de Maihold, trad. Madrid: Consejo Superior de Investigaciones Científicas, 2008.

Fitch, Brian T. Beckett and Babel: An Investigation into the Status of the Bilingual Work. Toronto: U of Toronto P, 1988.

Genette, Gérard. Palimpsestes: La littérature au second degré. Collection Poétique. Paris: Seuil, 1982.

Grayson, Jane. Nabokov Translated: A Comparison of Nabokov's Russian and English Prose. Oxford: Oxford UP, 1977. 
Grutman, Rainier. “Auto-translation.” Routledge Encyclopedia of Translation Studies. Mona Baker y Kirsten Malmkjær, eds. 1998. London: Routledge, 2001. 17-20. "Beckett and Beyond: Putting Self-Translation in Perspective." Orbis Litterarum 68/3 (2013): 188-206.

Hokenson, Jan y Marcella Munson. The Bilingual Text: History and Theory of Literary Self-Translation. Manchester: St. Jerome P, 2007.

Kaminsky, Amy K. After Exile: Writing the Latin American Diaspora. Minneapolis: U of Minnesota P, 1999.

Kanellos, Nicolás. Hispanic Immigrant Literature: El sueño del retorno. Austin: U of Texas P, 2011.

Karpinski, Eva C. Borrowed Tongues: Life Writing, Migration, and Translation. Waterloo: Wilfrid Laurier UP, 2012.

Klimkiewicz, Aurelia. "Self-Translation as Broken Narrativity: Towards an Understanding of the Self's Multilingual Dialogue." Self-Translation: Brokering Originality in Hybrid Culture. Anthony Cordingley, ed. London: Bloomsbury Academic, 2013. 189-201.

Lejeune, Philippe. Le Pacte Autobiographique. Collection Poétique. Paris: Seuil, 1975. López López-Gay, Patricia. "La autotraducción literaria: Traducibiliad, fidelidad, visibilidad. Análisis de las autototraducciones de Agustín Gómez Arcos y Jorge Semprún". Tesis de doctorado. Université Paris Diderot y Universidad Autónoma de Barcelona, 2008. <http:/www.tdx.cat/bitstream/handle/10803/5274/pllg1 de1. pdf? sequence $=1>$.

Macpherson, Heidi Slettedahl. Transatlantic Women's Literature. Edinburgh: Edinburgh UP, 2008.

McClennen, Sophia A. The Dialectics of Exile: Nation, Time, Language, and Space in Hispanic Literatures. West Lafayette: Purdue UP, 2004.

Ariel Dorfman: An Aesthetics of Hope. Durham: Duke UP, 2010.

Parcerisas, Francesc. "Sobre la autotraducción”. Quimera 210 (enero 2002): 13-14.

Perry, Menakhem. "Thematic and Structural Shifts in Autotranslations by Bilingual Hebrew-Yiddish Writers: The Case of Mendele Mokher Sbrim". Poetics Today 2/4 (1987): 181-92.

Polezzi, Loredana. Translating Travel: Contemporary Italian Travel Writing in English Translation. Aldershot: Ashgate, 2001.

Popovic, Anton. Dictionary for the Analysis of Literary Translation. Edmonton:

Department of Comparative Literature, The University of Alerta, 1976.

Risset, Jacqueline. “Joyce Translates Joyce.” Daniel Pick, trad. Comparative Criticism 6 (1984): 3-21.

Rushdie, Salman. Imaginary Homelands: Essays and Criticism, 1981-1991. London: New York: Granta Books, 1991. 
Steiner, George. After Babel: Aspects of Language and Translation. New York: Oxford UP, 1998.

Toury, Gideon. [1976]. "The Nature and Role of Norms in Literary Translation". Literature and Translation: New Perspectives in Literary Studies. J.S Holmes, J. Lambert and R. van den Broeck, eds. Leuven: acco, 1978. 83-100.

Venuti, Lawrence. The Translator's Invisibility: A History of Translation. London: Routledge, 1995. 
